\title{
Tail Plasma Domains and the Auroral Oval-Results of Mapping Based on the Tsyganenko 1989 Magnetosphere Model
}

\author{
D. ZWOLAKOWSKA and B. PoPIELAWSKA \\ Space Research Centre, Polish Academy of Science, ul. Bartycka 18a, 00-716 Warsaw, Poland
}

(Received January 7, 1992; Accepted May 8, 1992)

\begin{abstract}
We apply the magnetosphere model of TSYGANENKO (1989) to project into the ionosphere the tail plasma domains (with density $>0.1 \mathrm{~cm}^{-3}$ ) as measured by PROMICS-2 on Prognoz-8. The Plasma Sheet Boundary Layer (the separatrix layer) in our data is easily recognizable as a region distinct from the Central Plasma Sheet only when the plasma sheet expands at the beginning of substorm recovery. During weakly disturbed and quiet periods and at flanks the separatrix layer is not seen by our plasma instrument. However, when both the electron temperature and ion mass composition are taken into account we usually see three distinctly different plasma domains in the tail: the region A (we call it tentatively the warm envelope of the plasma sheet) dominated by the solar wind originated plasma with cold electrons $\left(T_{e} \leq 100 \mathrm{eV}\right)$, the region B (called here the high-latitude plasma sheet) with the electron temperature less than $1 \mathrm{keV}$, density fluctuations, irregular spectra and presence of cold oxygen ion beams (field aligned and/or conical) and the region $\mathrm{C}$ (called here the hot core of the plasma sheet) with electron energy density $\simeq 1 \mathrm{keV} / \mathrm{cm}^{3}$ where the hot oxygen ions dominate over the doubly ionized helium. This classification of plasma sheet subregions is similar to the one discussed by FELDSTEIN and GALPERIN (1985). We suggest that the warm envelope originates from the stagnating Low Latitude Boundary Layer. The warm envelope of the plasma sheet maps in most cases poleward of the statistical auroral oval of FeldsteinStarkov. The hot core of the plasma sheet maps into the equatorward half of the statistical oval and is connected to $R<15 \mathrm{R}_{\mathrm{E}}$ in the equatorial plane. The high latitude plasma sheet with the field aligned and/or conical $\mathrm{O}^{+}$beams maps immediately poleward and/or into the poleward half of the F-S oval and is mostly on the field lines which close at $R<60 \mathrm{R}_{\mathrm{E}}$.
\end{abstract}

\section{Introduction}

One of the most controversial problems in the auroral physics is related to the subject of aurora mapping to the corresponding regions in the magnetosphere. (For recent reviews see MENG and MAUK, 1991; SANDAHL et al., 1990; SISCOE, 1988; FELDSTEIN and GALPERIN, 1985.) There are several reasons why this problem is so long standing. One of them is lack of a realistic magnetic field model. With an advance of the new TSYGANENKO $(1987,1989)$ magnetosphere models which are tuned to proper modeling of the near tail with its thin current sheet the situation somewhat improved.

Another reason for problems with auroral mapping is related to lack of a widely approved terminology for different auroral luminosity structures to be mapped. We may refer to the statistical oval of discrete auroras of FELDSTEIN and STARKOV (1967) which is smooth and relatively wide, especially at higher $K_{p}$. On the other hand, 1-s auroral snapshots from Viking reveal that the instantaneous auroral distribution usually splits into the relatively thin and 
smooth belt continuous at all local times and the dynamic, discrete features connected to the continuous oval but protruding deeply into the dark region poleward of it. The continuous oval on Viking's pictures is seen as a diffuse band of emissions delineating the most equatorward extent of the instantaneous auroral distribution (ELPHINSTONE et al., 1990). From the ground it is seen as an active (even during quiet period) narrow rayed arc extending from the evening through midnight to the morning side (SHEPHERD et al., 1990). The auroral substorm manifest itself not only in brightening and widening of the continuous oval but also in complex transformation of the poleward region of discrete arcs (SANDAHL et al., 1990; SHEPHERD et al., 1990; ELPHINSTONE et al., 1991a). The instantaneous auroral distribution taking together the continuous oval and poleward discrete structures in the midnight sector may extend, e.g., from $64^{\circ}$ to $76^{\circ}$ geomagnetic latitude (SANDAHL et al., 1990). The continuous oval itself can be wide during the substorm when at the onset a bulge of enhanced emissions forms in the midnight sector followed by poleward expansion as well as the westward/eastward propagation of disturbance along the oval (e.g., CRAVEN and FRANK, 1990). Several degrees of latitude wide auroral distribution will project into the vast expanse of the magnetospheric tail comprising different plasma regimes. So, one should specify each time what is to be mapped, e.g., the thin continuous oval, the poleward discrete features connected to the oval or the widened substormtime oval. ELPHINSTONE et al. (1991a, b) mapped Viking's instantaneous auroral distribution along the magnetic field lines into the magnetosphere using Tsyganenko 1987 magnetic field model. They found that the thin continuous auroral oval lies on closed magnetic field lines crossing the equatorial plane in the region of maximum cross-tail current at XGSM $\simeq-6 R_{E}$. The poleward boundary of the thin continuous oval may map as close as at XGSM $\simeq-10 R_{E}$ in the equatorial plane, but the arc system in the midnight sector poleward and parallel to the main auroral distribution maps as far as at $\mathrm{XGSM}=50-60 \mathrm{R}_{\mathrm{E}}$ in the tail what is close to the model boundary between open and closed magnetic field lines in the tail.

It should be mentioned that such a geometrical mapping strongly depends on the magnetic field model and should be confirmed by independent analysis relating different auroral luminosity structures and accompanying particle precipitation (so called Boundary Plasma Sheet and Central Plasma Sheet precipitation - for a recent review see, e.g., SANDAHL et al., 1990) with the relevant source plasma observations in the tail. Here we come to another difficulty related with auroral mapping. It seems that in spite of years of measurements we have no comprehensive classification of tail plasma domains. The main plasma region in the tail is the plasma sheet. The simplistic division of the plasma sheet into the Central Plasma Sheet and its outer "skin", the Plasma Sheet Boundary Layer equivalent to the separatrix layer between closed and open magnetic field lines where the counterstreaming ion beams appear (EASTMAN et al., 1984, 1985; TAKAHASHI and HONES, 1988) seems not to describe the plasma sheet structure in a complete way. E.g., such a region, found on Prognoz-8, as "the hot plasma in tail lobes" apparently above the plasma sheet proper as reported by JIMENEZ et al. (1984) (see also BELOVA et al., 1987) is not taken into account. Moreover, the PSBL footprint in the ionosphere should be marked by a narrow region $\left(\simeq 1^{\circ}\right.$ of latitude) of velocity dispersed ion precipitation at the poleward boundary of the main BPS precipitation region as pointed by ZELENYI et al. (1990). Immediately the question arises where the rest of BPS precipitation region maps in the magnetosphere.

Another classification of plasma sheet subregions proposed mainly in Russian literature is extensively presented and discussed by FELDSTEIN and GALPERIN (1985). They distinguish the central (low latitude or main) part of the plasma sheet populated by electrons with mean 
energy $\sim 1 \mathrm{keV}$ and the outer (high-latitude) plasma sheet populated by softer electrons with the average energy decreasing to $\sim 0.4 \mathrm{keV}$. These two classifications, the one based on the 3 dimensional plasma measurements and distinguishing regions with different shape of the ion distribution function (beams in PSBL vs isotropic distribution in CPS) and the other, based on the average values of moments of the electron distribution function both seem not to tell the whole story about the plasma sheet structure. According to our opinion a more detailed classification of tail plasma domains is necessary to remove rest of our problems with auroral mapping.

We propose an alternative tail plasma classification based on the combined criteria taking into account the range and variability of plasma parameters (electron temperature and density), the ion mass composition $\left(\mathrm{H}^{+}, \mathrm{He}^{++}\right.$and $\left.\mathrm{O}^{+}\right)$, the plasma wave activity and the shape of plasma distribution function for $\mathrm{O}^{+}$(cold beams or hot isotropic oxygen plasma).

This study is an extension and complementation of an earlier Prognoz-8 study of the tail plasma domains (JIMENEZ et al., 1984; BELOVA et al., 1987). This earlier study was based on the data from the Russian SKS plasma instrument with limited possibility of ion mass composition diagnosis as well as the narrower energy range and solid angle coverage than PROMICS-2.

\section{Instrumentation and Orbit}

Plasma data are from PROMICS-2. PROMICS-2 was the second in a series of SwedishRussian collaborative experiments (R. Lundin was the principal investigator). It consisted of three energetic ion composition spectrometers (ICS). Two ICS:s (D1 and D2) were oriented perpendicularly to the spin axis and covered the energy range $0.05-19 \mathrm{keV}$. The third (D6, $0.27-4.4 \mathrm{keV}$ ) was oriented $10^{\circ}$ from the spin axis (which was parallel to the ecliptic plane and directed toward the sun). The experiment also comprised three E/Q charged particle spectrometers measuring positive ions and electrons in the energy range $30 \mathrm{eV}-40 \mathrm{keV}$. Mainly the basic, low speed mode of operation (so called "solar wind mode") was available during the analysed period. In this mode ion and electron energy spectra from D3 and D4 were obtained in 32 steps during 330 seconds (while the spin period was $~ 120$ s). ICS D6 gave 3 spectra of $\mathrm{H}^{+}$and $\mathrm{He}^{++}$and one spectrum of $\mathrm{O}^{+}$(all in 16 steps with full spectrum scanned in $4.86 \mathrm{~s}$ ) within one spin period every 20 minutes. D1 and D2 ICS:s were in an integral mode and measured an integral flux of four ions $\left(\mathrm{D} 1-\mathrm{He}^{++}, \mathrm{O}^{+} ; \mathrm{D} 2-\mathrm{He}^{+}, \mathrm{H}^{+}\right)$in the energy range $0.05-16 \mathrm{keV}$ every $20 \mathrm{~s}$. Wave experiment consisted of a double probe as a sensor and an aboard spectrum analyser which measured the spectral densities of electric field fluctuations in the range 2-105 Hz at 9 frequencies (bandwidth $\sim 2 \mathrm{~Hz}$ ). Full spectrum was obtained every $30 \mathrm{~s}$.

Prognoz-8 had highly elliptical orbit with inclination angle $65^{\circ}$ and apogee $\sim 30 \mathrm{R}_{\mathrm{E}}$. Satellite trajectory in GSM coordinates is shown in Figs. 1(a) and 1(b) (the ordinate axis is the distance to the model neutral sheet along the ZGSM or ZSM axis).

\section{Tail Plasma Domains}

We take into account all plasma samples with the ion density $N>0.1 \mathrm{~cm}^{-3}$ excluding strongly flowing mantle or LLBL when adjacent to the magnetopause. According to our analysis of 11 tail crossings (marked on the pictures by numbers as in the Table 1) the following plasma domains can be found in the tail: 


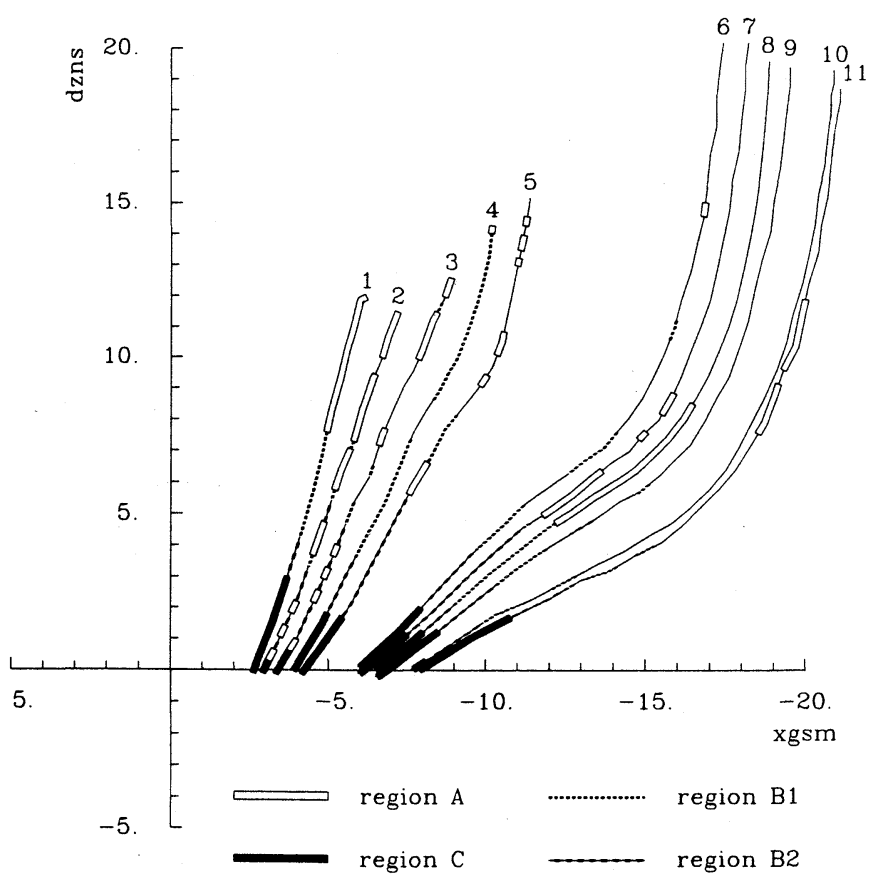

Fig. 1(a). Prognoz-8 trajectory in XGSM-DZNS coordinates. DZNS is a distance to the model neutral sheet along ZGSM axis or along ZSM axis (for $R \leq 10 \mathrm{R}_{\mathrm{E}}$ ) respectively according to GosLING et al. (1986) or LoPEZ (1990).

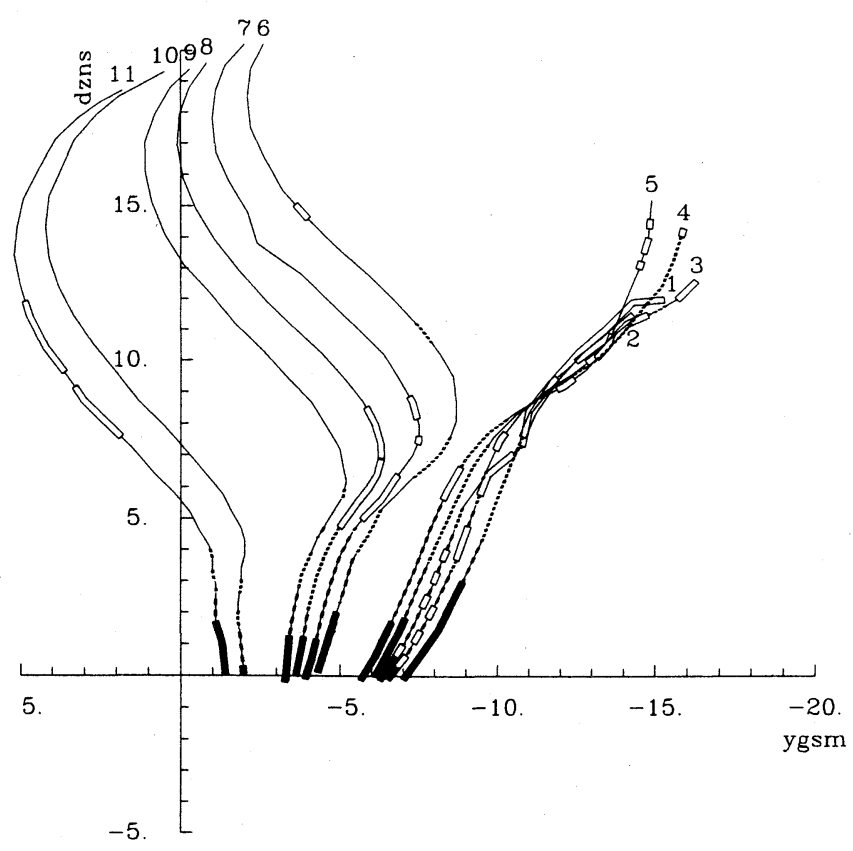

Fig. 1(b). Prognoz-8 trajectory in YGSM-DZNS coordinates. Plasma domains are marked as described in Fig. 1(a). 
Table 1. Prognoz-8 tail crossings.

\begin{tabular}{rcccc}
\hline No. & DTP No. & Start & End & Average $K_{p}$ \\
\hline 1 & 168 & $04: 0019.07 .81$ & $15: 0019.07 .81$ & $2+$ \\
2 & 171 & $04: 0023.08 .81$ & $14: 2523.07 .81$ & $4+$ \\
3 & 174 & $00: 0027.07 .81$ & $13: 4027.07 .81$ & $4+$ \\
4 & 176 & $22: 0030.07 .81$ & $13: 0031.07 .81$ & $2+$ \\
5 & 180 & $16: 0003.08 .81$ & $12: 2504.08 .81$ & $3+$ \\
6 & 190 & $03: 0023.08 .81$ & $09: 0524.08 .81$ & $4+$ \\
7 & 194 & $03: 0027.08 .81$ & $08: 2528.08 .81$ & $3+$ \\
8 & 196 & $21: 0030.08 .81$ & $07: 4501.09 .81$ & $0+$ \\
9 & 199 & $04: 0004.09 .81$ & $07: 0505.09 .81$ & $3^{\circ}$ \\
10 & 211 & $16: 0015.09 .81$ & $04: 4717.09 .81$ & $2^{\circ}$ \\
11 & 213 & $18: 0019.09 .81$ & $04: 0021.09 .81$ & $3+$ \\
\hline
\end{tabular}

${ }^{*} \mathrm{DTP}=$ data taking period. ${ }^{* *}$ Time of the neutral sheet crossing.

- a domain type A: a region of relatively dense (up to several ions per $\mathrm{cm}^{3}$ ) and warm plasma with $T_{e} \leq 0.1 \mathrm{keV}$ (usually $\kappa$-distribution with $k T=30-50 \mathrm{eV}$ and $\kappa=2-5$ ), with significant fluxes of $\mathrm{He}^{++}$seen in denser regions (the $\mathrm{He}^{++} / \mathrm{H}^{+}$ratio of integral flux in the energy range $0.05-16 \mathrm{keV}$ is typically $0.04-0.02)$. This plasma may be pervaded by cold ( $k T$ $\sim 5 \mathrm{eV}, E \simeq 100 \mathrm{eV}-1 \mathrm{keV}$ ) and field aligned oxygen beams, the same which are often seen in the lobes. We tentatively name this region the warm envelope of the plasma sheet. An example of plasma data registered within the domain A is shown in Fig. 2. These data come from a moderately disturbed period $(A E=200-450 \gamma)$ of quasi-stationary convection. Prior to $\sim 00: 34$ UT (August 28, 1981) the satellite was in the lobe. The exit from the domain A back into the lobe took place about half an hour later than shown in the Fig. 2 and is related to the plasma sheet thinning before a sudden and giant impulse in $A E$ indices $(\delta A E \simeq 400 \gamma)$ at $\approx 03: 25$ UT. The hot post-break up plasma sheet with separatrix signatures at the boundary reached the satellite at 03:49 UT (not shown in Fig. 2).

- a domain type $\mathrm{B}: \mathrm{He}^{++}$depressed in comparison to the warm envelope, instead, as a rule, $\mathrm{O}^{+}$are observed in the form of field aligned beams (at highest latitudes) and/or conical beams. Most spectacular $\mathrm{O}^{+}$beam events are related to substorm activity. Electron temperature is $0.2-$ $0.5 \mathrm{keV}$ in its outermost part (domain B1) and up to $1 \mathrm{keV}$ further into the sheet (domain B2). Density is less than $1 \mathrm{~cm}^{-3}$, fluctuations of $N$ are observed. For the domain B the most characteristic is the strong wave activity at frequencies less than $100 \mathrm{~Hz}$. The domain $\mathrm{B}$ is also most variable in response to substorm activity. It is named the high-latitude plasma sheet because the electron average energies are the same as characteristic for the region called the outer (highlatitude) plasma sheet by FELDSTEIN and GALPERIN (1985). An example of plasma data registered within the domain $\mathrm{B}$ is shown in Fig. 3. These observations were made during a strong substorm (maximum $A E \approx 900 \gamma$ at 03:15 UT). The substorm expansion phase started at about 02:55 UT (the satellite was in the lobe at that time). The substorm recovery began at 04:00 UT and lasted up to 06:00 UT when $A E$ dropped to $~ 50 \gamma$. Later (not shown in the Fig. 3 ) the satellite registered the quiet HLPS (with less intense $\mathrm{O}^{+}$beams) and at 08:35 UT entered the hot core.

- a domain type C: $T_{e} \geq 1 \mathrm{keV}, n \simeq 1 \mathrm{~cm}^{-3}$, wave activity completely suppressed, oxygen fluxes are hot $(\sim 1 \mathrm{keV})$ and isotropic - no beams, electron and hydrogen ion fluxes are also 


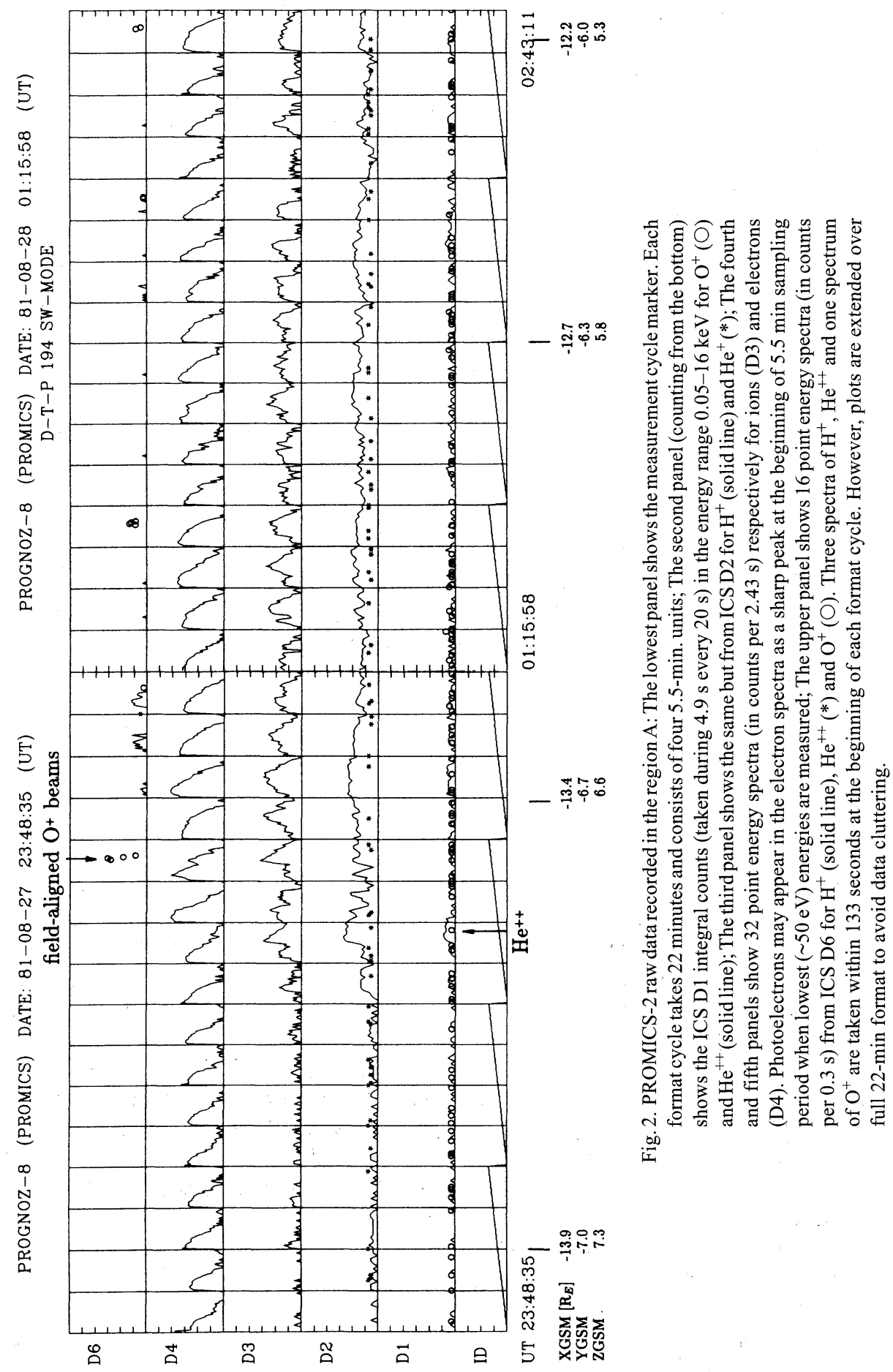


Tail Plasma Domains and the Auroral Oval
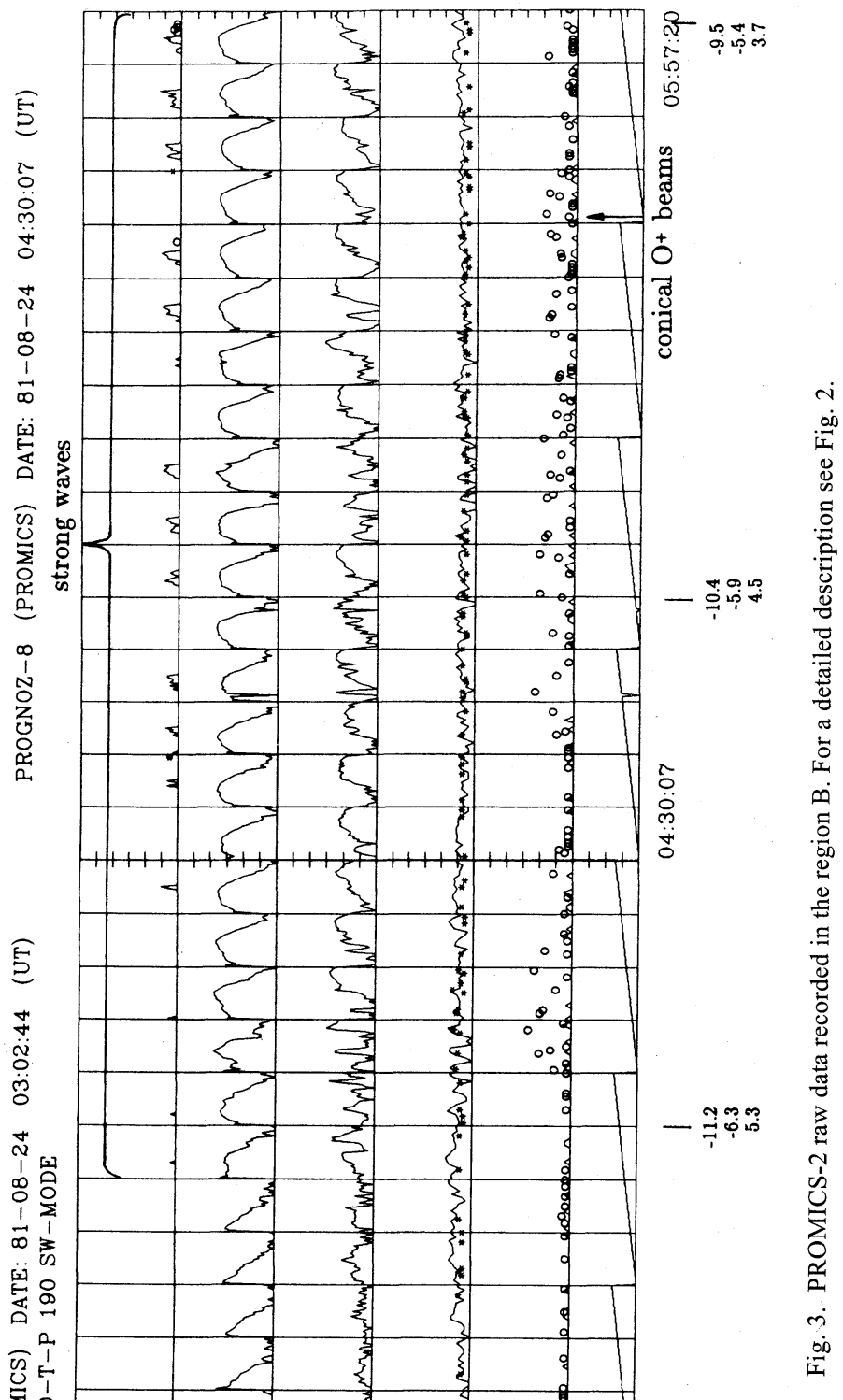


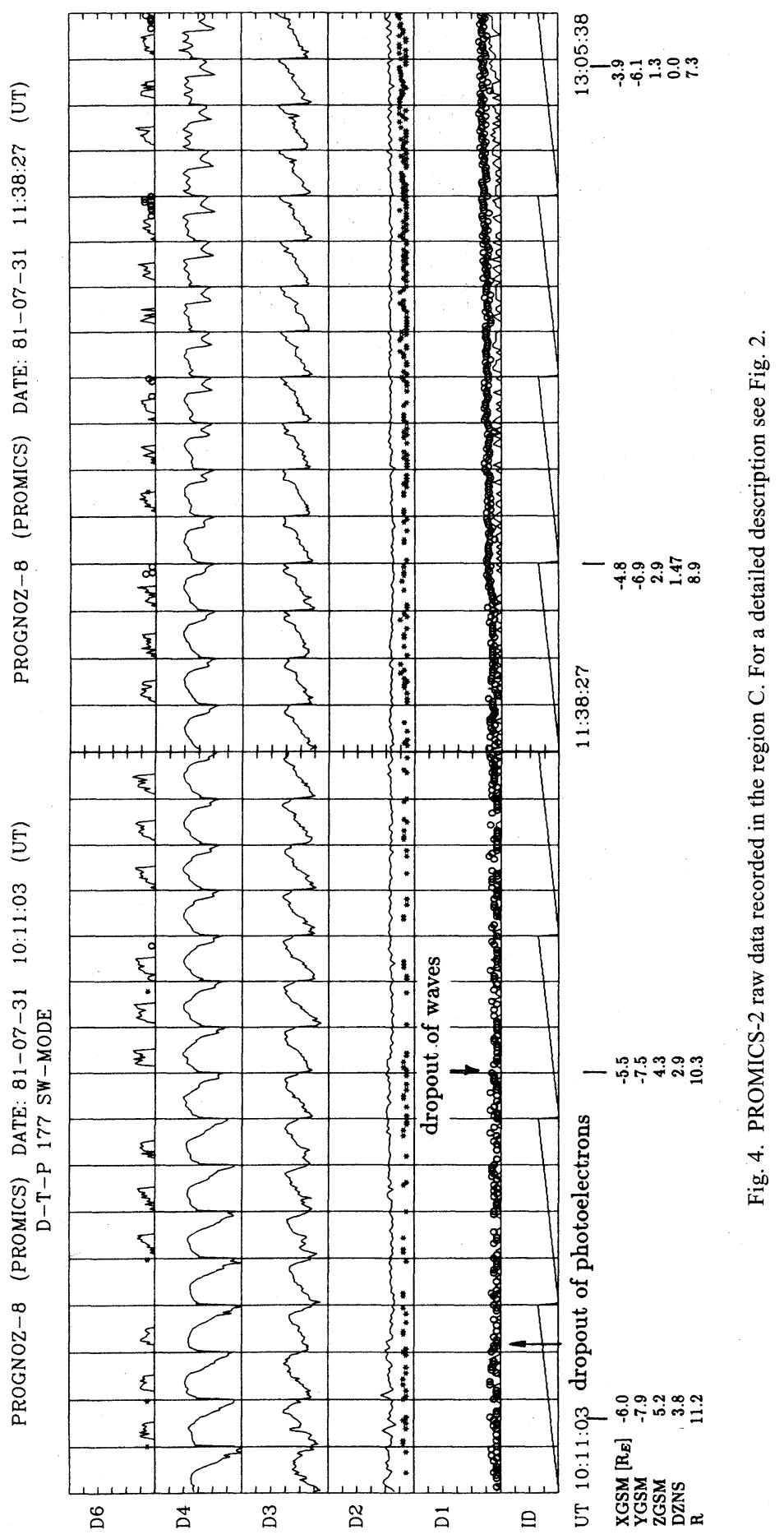


isotropic with neither strong flow signatures nor density fluctuations (both present in the domain B). Prognoz-8 photoelectron fluxes are near background in this region. The boundary of the region $\mathrm{C}$ is most easily distinguished just by a sudden dropout of the photoelectron fluxes as measured by SKS plasma instrument ( $E \geq 18 \mathrm{eV}$ ) (JIMENEZ et al., 1984). This domain is tentatively named the hot core of the plasma sheet and is the same region as the low-latitude (central or main) plasma sheet discussed by Feldstein and Galperin. An example of plasma data registered within the domain $\mathrm{C}$ is shown in Fig. 4. These observations were made during quiet period $(A E \sim 50 \gamma$ ) following a strong substorm (maximum $A E \approx 600 \gamma$ at 06:15 UT). Photoelectron dropout on SKS took place at about 10:30 UT, and low frequency electric field fluctuations ceased at 11:00 UT. Starting at 10:54 UT, a population of high energy electrons $(E>20 \mathrm{keV})$ appeared as indicated by an increased count rate in the high energy range of D4 spectrometer. The nominal neutral sheet (LOPEZ, 1990) was crossed at 13:00 UT. Near the neutral sheet the satellite spin plane is nearly tangent to the magnetic field line so the loss cone and $90^{\circ}$ pitch angle are scanned 2 times every 120 s spin period and 5 or 6 times during 330 $\mathrm{s}$ energy sampling period. The spin modulation of counting rates with 5 or 6 maxima during $330 \mathrm{~s}$ indicates either trapped (maximum at $90^{\circ}$ ) or butterfly (minimum at $90^{\circ}$ ) pitch angle distributions. Note that $\mathrm{O}^{+}$fluxes from $\mathrm{D} 1$ in the hot core are isotropic in contradistinction to the region $\mathrm{B}$ where the cold beams of $\mathrm{O}^{+}$are mostly observed. The ratio $\mathrm{O}^{+} / \mathrm{He}^{++}$of integral fluxes from D1 ICS is much higher than 1 in the hot core.

Limited data set of only 11 tail crossings during very different geomagnetic conditions (from super quiet, $A E<50 \gamma$ - case No. 6 to strongly disturbed, $A E \approx 1500 \gamma$ - case No. 2 and 3 ) does not allow us to make any well founded statistical studies of the variability in location and properties of the different plasma domains as a function of magnetic activity. However, some regularities are immediately evident. E.g., the domain $\mathrm{A}$ is especially extended along ZGSM axis during northward IMF periods and at flanks (ZWOLAKOWSKA et al., 1992). During disturbed conditions it may appear in the growth phase of substorm and then disappears at the expansion. When the domain $\mathrm{A}$ is contiguous to the main body of the plasma sheet, there are no clear signatures of the separatrix layer at the boundary of plasma sheet - a relatively smooth transition is observed between the lobe and the domain $\mathrm{A}$ as well as between the domains $\mathrm{A}$ and B. In two cases (events 2 and 3) of strong substorm activity the domain A was observed to penetrate deeply into the region normally occupied by the domain C. Details of these events and the interpretation are given in (POPIELAWSKA et al., 1992; KOPERSKI and POPIELAWSKA, 1992). It would be interesting to know whether the penetration of cold plasma $\left(T_{e} \leq 100 \mathrm{eV}\right)$ into the equatorial inner magnetosphere $\left(R<10 \mathrm{R}_{\mathrm{E}}\right)$ is a rule during strong substorms.

The location of the domain $B$ seems to be most variable in response to substorms. This domain may expand to more than $10 \mathrm{R}_{\mathrm{E}}$ above the neutral sheet (case No. 4 and 6) at the beginning of substorm recovery and be absent as close $\sim 0.5 \mathrm{R}_{\mathrm{E}}$ above neutral sheet just before the sudden increase of $A E$ in course of substorm expansion phase (case No. 2 and 3). From this point of view a least easy to budge is the domain $\mathrm{C}$ as its outer (high-latitude) boundary varies merely between $\sim 3 \mathrm{R}_{\mathrm{E}}$ and $\sim 0.5 \mathrm{R}_{\mathrm{E}}$ above the neutral sheet (at $R<15 \mathrm{R}_{\mathrm{E}}$ ).

The hot core partially overlaps the ring current region. However, both the satellite orbit and the plasma instrument are not well suited for measurements in this interesting region of the magnetosphere. Moreover, we have neither the precise measurements of the magnetic field nor the information on the instantaneous satellite orientation. Both are necessary for interpretation of plasma and energetic particle measurements in a region with significant gradients of $\boldsymbol{B}$. 


\section{Tail Plasma Domain Mapping}

These 3 plasma domains are mapped with the help of T89 model (for the actual $K_{p}$ ) and IGRF 1980 inward into the ionosphere as shown in Fig. 5, and outward into the $\min |B|$ surface as shown in Fig. 6. Low-altitude projections (in the corrected geomagnetic latitude-corrected MLT coordinates) are compared with the position of the statistical auroral oval of FELDSTEIN and STARKOV (1967). The FS auroral oval is a good reference frame for statistical studies on the auroral ionosphere-magnetosphere coupling and represents an average (for given $Q, K_{p}$ or $A E)$ region where discrete aurorae appear at an observer's zenith.

The results are following:

- The domain A partially lies on the field lines which may be open as they reach the flank magnetopause or the distant tail at $R \geq 60 \mathrm{R}_{\mathrm{E}}$. This domain maps well poleward of the FS oval during quiet conditions. During disturbed periods it maps immediately poleward or even into the oval itself (events 2 and 3), and in such cases it is on closed T89 model field lines.

- The domain B1 (with $T_{e}=0.2-0.5 \mathrm{keV}$ ) lies partially on the field lines connected to the distant tail $\left(R \geq 60 \mathrm{R}_{\mathrm{E}}\right)$ and maps immediately poleward of the FS oval.

- The domain $\mathrm{B} 2$ lies on the field lines which close at $R \leq 50 \mathrm{R}_{\mathrm{E}}$ and maps into the poleward half of the auroral oval. With increasing activity this region encompasses the field lines mapping to progressively lower latitudes within the oval.

- The domain $\mathrm{C}$ often maps into the equatorward half of the oval. For the two flank

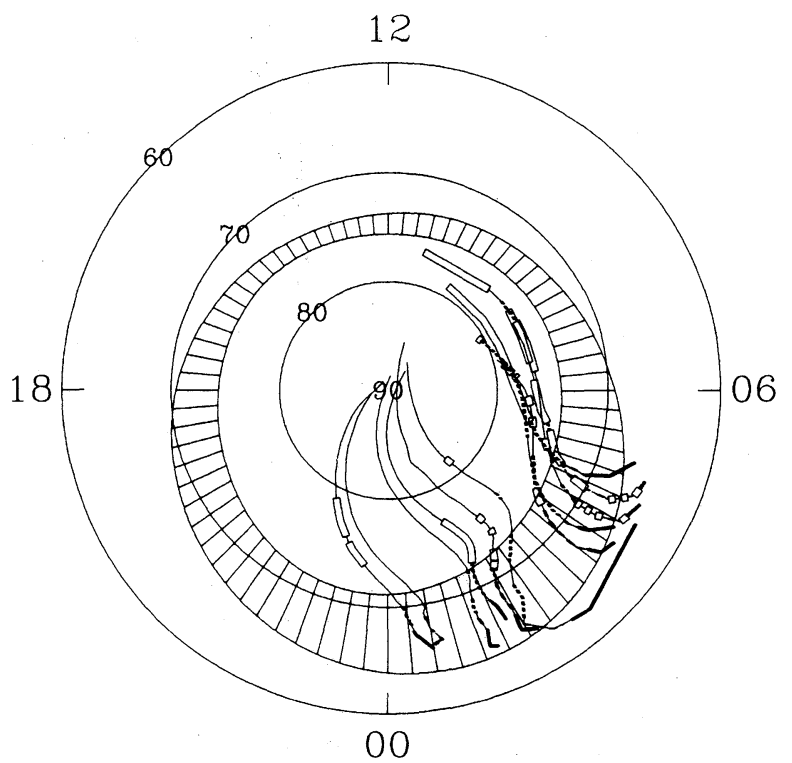

Fig. 5. Projection of the tail plasma domains (at DZNS $\geq 0$ ) into the ionosphere. The auroral oval position of FeLdSTEIN and StARKov (1967) for $K_{p}=3^{+}$is shaded. Plasma domains are marked as described in Fig. 1(a). Lines crossing the corrected latitude $70^{\circ}$ in the clockwise order starting at $\sim 06 \mathrm{MLT}$ represent the tail traversals No. $1-11$, respectively. 


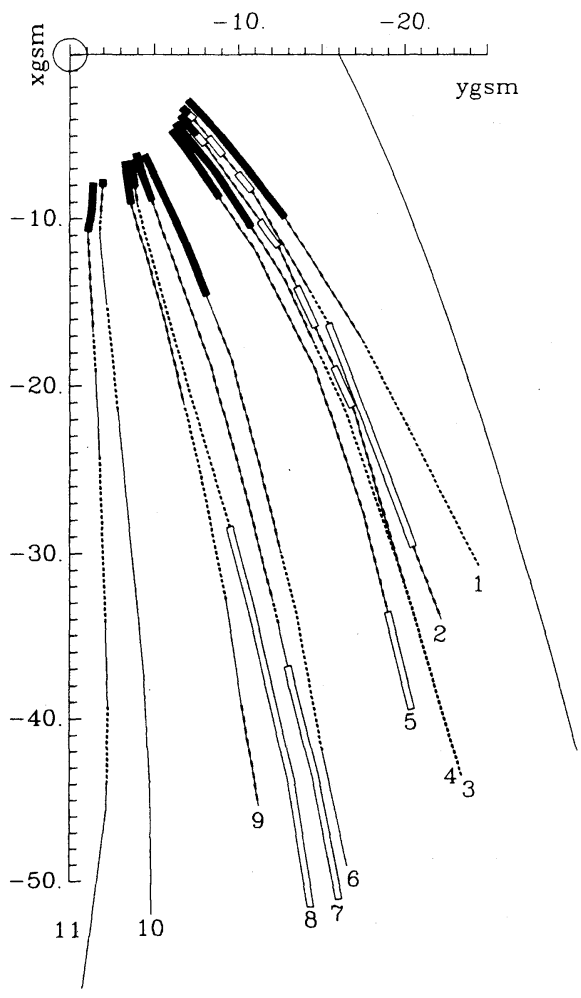

Fig. 6. Mapping of tail plasma domains (at DZNS $\geq 0$ ) into the min $|B|$ surface (in YGSM-XGSM coordinates). Plasma domains are marked as described in Fig. 1(a).

crossings during weakly disturbed period the projection of the domain $\mathrm{C}$ covered the full range of auroral latitudes for the appropriate $K_{p}$. With increasing activity the hot core is found at field lines projecting into lower latitudes up to the equatorward boundary of the FS oval. The domain $\mathrm{C}$ is connected to $R \leq 15$ equatorial distances on the $\min |B|$ surface.

All field lines coming out the statistical auroral oval close at geocentric distances $R \leq 60$ $\mathrm{R}_{\mathrm{E}}$. The poleward boundary of the FS oval traces approximately the expected boundary between the LLBL and the plasma sheet in the equatorial plane. The 1989 magnetosphere model of Tsyganenko does not contain a near-Earth neutral line, even for most disturbed conditions. This model gives merely a local minimum of the magnetic field line curvature radius at $10-15 \mathrm{R}_{\mathrm{E}}$ in the equatorial midnight region. If the near-Earth neutral line forms in the tail during substorms, some of our mapping results may be far from reality.

\section{Summary and Discussion}

When Tsyganenko 1989 model is used for mapping, the statistical oval appears to be connected to the vast magnetospheric reservoir of plasma between $R \sim 5-7 \mathrm{R}_{\mathrm{E}}$ to $R \simeq 60 \mathrm{R}_{\mathrm{E}}$. This region is populated by at least 3 different plasma domains. The equatorward half of the 
FS auroral oval is connected to $R \leq 15$ geocentric distances occupied by a hot core of the PS. Rest of the oval maps into the high latitude plasma sheet - the most dynamical tail plasma domain. The warm envelope of the plasma sheet (northward IMF) maps well poleward of the FS oval during quiet conditions. We suggest that this plasma is a source of the high latitude arcs delineating the "inner" auroral oval of ELPHINSTONE et al. (1990).

The relation of PSBL (the separatrix layer) to our warm envelope and the high latitude plasma sheet is unclear. Distinct separatrix signatures are seen in PROMICS-2 data only at the edge of the high latitude plasma sheet when the plasma sheet expands at the beginning of substorm recovery. In such situations we see higher energy electrons coming up to 5 min earlier than the post-break up hot ions. Our detector D6 looking toward the Sun is able to see only the slowest and coolest PSBL beams from the range specified by TAKAHASHI and HONES (1988). So, we cannot see the region of the velocity dispersed ion beams (as well as the earthward flowing beams) and the actual extent of the PSBL is unknown. However, the high latitude plasma sheet is sometimes so extended along Z-axis that it rather cannot constitute the PSBL as a whole. The typical PSBL traversal time range from a fraction of minute to more than 10 minutes with mean values of about 5-6 minutes according to BAUMJOHANN et al. (1988). These authors used a photoelectron signature as a fiducial mark of boundary between the PSBL and CPS. At Prognoz-8 we usually see the photoelectron flux drop-out (at $E>18 \mathrm{eV}$ ) just before the entrance into the hot core of the plasma sheet.

Our results are only in partial agreement with results of JIMENEZ et al. (1984). Our warm envelope is called by them "the hot plasma in the lobes" ("hot" in opposition to the cold ion beams usually found in the lobes). Their interpretation is based on the revealed by them "similarity of the characteristics of the rarefied plasma in the tail and the denser plasma sheet". They suggest the plasma sheet origin of this "hot plasma in the lobes". BELOVA et al. (1987) proposed the Kelvin-Helmholz instability of the plasma sheet surface as a source of the detached "hot" plasma in the tail. However, as was shown above, the warm envelope is often denser and always much cooler than the main body of the plasma sheet (HLPS and the hot core). High content of $\mathrm{He}^{++}$allows us to suggest that the source of this plasma domain is the stagnating LLBL. EASTMAN et al. (1985) also found the cold plasma component within the plasma sheet and suggested that this cold component comes directly from the flank LLBL. The horizontal transport of the LLBL plasma from flanks into the central part of the tail must be very effective especially during the northward IMF conditions.

Jimenez et al. mapped their plasma domains using the Mead-Fairfield magnetosphere model and the dipole internal field. With differences in details, result of mapping is similar to our mapping: "hot plasma in the lobes" maps poleward of the Feldstein-Starkov oval. Their CPS samples are in most cases equivalent to our hot core samples and for this region the differences in mapping are substantial as their CPS projections overlap the whole oval latitude range, while our hot core projections are mainly in the equatorward half of the oval.

Ion mass composition of discussed plasma domains is in perfect agreement with the statistical results of LENNARTSSON $(1987,1988)$. He found the significant fluxes of $\mathrm{He}^{++}$and dense plasma sheet during quiet conditions with northward IMF when we see the extended and dense warm envelope. During disturbed conditions the warm envelope thins or disappears and the HLPS with its intense cold oxygen beams is more extended. In such a way the transition realizes from the quiet-time plasma sheet to the hot and less dense plasma sheet with high oxygen content typical for disturbed conditions. 
Authors are grateful to Prof. R. Lundin from Kiruna for PROMICS-2 data. The wave instrument on Prognoz-8 was a collaborative Polish-Russian experiment. Dr. S. Klimov from IKI, Moscow was P. I., Dr. P. Oberc from SRC in Warsaw was co-P. I.

\section{REFERENCES}

Baumjohann, W., G. Paschmann, N. Sckopke, C. A. Cattell, and C. W. Carlson, Average ion moments in the Plasma Sheet Boundary Layer, J. Geophys. Res., 93, 11507-11520, 1988.

Belova, E. V., O. L. Vaisberg, L. M. Zelenyi, and R. A. Jimenez, Origin of plasma clouds in the high-latitude regions of the magnetospheric tail, Kosmich. Issled., XXV(4), 606-619, 1987 (in Russian).

Craven, J. D. and L. A. Frank, Diagnosis of auroral dynamics using global auroral imaging with emphasis on largescale evolutions, in Auroral Physics, edited by C. T. Meng, M. J. Rycroft, and L. A. Frank, p. 249, Cambridge University Press, Cambridge, 1990.

Eastman, T. E., L. A. Frank, W. K. Peterson, and W. Lennartsson, The plasma sheet boundary layer, J. Geophys. Res., 89, 1553-1572, 1984.

EASTMAn, T. E., L. A. Frank, and C. Y. HuANG, The boundary layers as the primary transport regions of the Earth's Magnetotail, J. Geophys. Res., 90, 9541-9560, 1985.

Elphinstone, R. D., K. Jankowska, J. S. Murphree, and L. L. Cogger, The configuration of the auroral distribution for interplanetary magnetic field $B_{z}$ northward, 1. IMF $B_{x}$ and $B_{y}$ dependencies as observed by the Viking satellite, J. Geophys. Res., 95, 5791-5804, 1990.

Elphinstone, R. D., L. L. Cogger, D. Hearn, and M. G. Henderson, Observations of changes of the auroral distribution prior to substorm onset, accepted to AGUMonograph on Magnetospheric Substorms, 23 pp., Hakura Conference, Japan, 1991a.

Elphinstone, R. D., D. Hearn, J. S. Murphree, and L. L. Cogger, Mapping using the Tsyganenko long magnetospheric model and its relationship to Viking auroral images, J. Geophys. Res., 96, 1467-1480, $1991 \mathrm{~b}$.

Feldstein, Y. I. and G. V. StaRkov, Dynamics of auroral belt and polar geomagnetic disturbances, Planet. Space Sci., 15, 209-229, 1967.

Feldstein, Y. I. and Yu. I. GALPERIN, The auroral luminosity structure in the high-latitude upper atmosphere: its dynamics and relationship to the large scale structure of the Earth's Magnetosphere, Rev. Geophys., 23, $217-$ $275,1985$.

Gosling, J. T., D. J. McComas, M. F. Thomsen, and S. J BAmE, The warped neutral sheet and plasma sheet in the near-Earth geomagnetic tail, J. Geophys. Res., 91, 7093-7099, 1986.

Jimenez, R., S. A. Romanow, O. L. VAisberg, and V. M. Balebanow, Characteristics of plasma fluxes in the geomagnetotail according to measurements on Prognoz-8, 58 pp., preprint 930, IKI AN, Moscow, 1984.

KoPERSKI, P. and B. PopielawSKA, Observations of cold electrons and strong low-frequency electric field fluctuations close to the neutral sheet at $R=8 \mathrm{R}_{\mathrm{E}}$, Proceedings of the International Conference on Substorms-ICS1, Kiruna, 1992 (ESA SP-335, May 1992), 359-364, 1992.

Lennartsson, W., Dynamical features of the plasma sheet ion composition, density and energy, in Magnetotail Physics, edited by A. T. Y. Lui, pp. 35-40, The Johns Hopkins University Press, Baltimore and London, 1987.

LENnARTSSON, W., Comparison of plasma sheet ion composition with the IMF and solar wind plasma, Adv. Space Res., 8, 135-138, 1988.

LOPEZ, R. E., The position of the magnetotail neutral sheet in the near-Earth region, Geophys. Res. Lett., 17, 1617$1620,1990$.

MENG, C.-I. and B. H. MAUK, Global auroral morphology: Quadrennial report to the I.U.G.G. on U.S. Contributions, Rev. Geophys., Supplement, 1028-1038, 1991.

Popielawska, B., P. Koperski, D. Zwolakowska, R. Lundin, and A. V. Zakharov, On the low energy $(E \geq 50$ $\mathrm{eV}$ ) electrons in the magnetotail, Adv. Space Res., 1992 (in press).

Sandahl, I., L. Eliasson, A. Pellinen-Wannberg, G. Rostoker, L. P. Block, R. E. Erlandson, E. FrissChristensen, B. Jacobsen, H. LuHR, and J. S. Murphree, Distribution of auroral precipitation at midnight during a magnetic storm, J. Geophys. Res., 95, 6051-6072, 1990.

SHePHerd, G. G., A. SteEn, and J. S. MurPhree, Auroral boundary dynamics observed simultaneously from the Viking spacecraft and from the ground, J. Geophys. Res., 95, 5845-5865, 1990.

Siscoe, G. L., Meeting Reports: Auroral Physics, A Chapman Memorial, Eos, Trans. A.G.U., 69, 1586, 1988.

TAKAHASHI, K. and E. W. HoNES, Jr., ISEE-1 and 2 observations of ion distributions at the plasma sheet-tail lobe 
boundary, J. Geophys. Res., 93, 8558-8582, 1988.

Tsyganenko, N. A., Global quantitative models of the geomagnetic field in the cislunar magnetosphere for different disturbance levels, Planet. Space Sci., 35, 1347-1358, 1987.

Tsyganenko, N. A., A magnetospheric magnetic model with a warped tail current sheet, Planet. Space Sci., 37, 5$20,1989$.

ZELENYI, L. M., R. A. KovRAZHKIN, and J. M. BosQUED, Velocity dispersed ion beams in the nightside auroral zone: Aureol 3 observations, J. Geophys. Res., 95, 12119-12139, 1990.

Zwolakowska, D., P. Koperski, and B. Popielawska, Plasma populations in the tail during northward IMF, Proceedings of the International Conference on Substorms-ICS-1, Kiruna, 1992 (ESA SP-335, May 1992), 57-62, 1992. 